\title{
Awards Presented at the 50th Annual Meeting of the BEHAVIOR GENETICS ASSOCIATION Held Online on Friday, June 262020
}

(c) Springer Science+Business Media, LLC, part of Springer Nature 2020

The Association's annual awards were announced by email following the online meeting.

The 43rd Annual Thompson Award for the best oral presentation by an associate member was awarded to Jared Balbona (Institute for Behavioral Genetics, University of Colorado, Boulder) for his presentation "The Nature of Nurture Revisited: Estimating the Effect of Vertical Transmission using Structural Equation Modeling" and Rosa Cheesman (Social, Genetic \& Developmental Psychiatry Centre, King's College, London) for her presentation "Genetic associations between non-cognitive skills and educational outcomes: The role of parental environment."

The 8th Annual Rowe Award for the best poster presentation by an associate member was awarded to Claire Morrison (Institute for Behavioral Genetics, University of Colorado, Boulder) for her poster "Latent genetic structure of sleep health and psychopathology."

The 20th Annual Fulker Award for the outstanding paper in Behavior Genetics during the past year was presented at the business meeting by John Hewitt, to Daniela Schneider for the paper "Symbiont-Driven Male Mating Success in the Neotropical Drosophila paulistorum Superspecies".
The Fuller and Scott Award for outstanding early career contributions to the field and the Dobzhansky Award for outstanding lifetime contributions to the field of behavior genetics were not awarded.

Respectfully Submitted,

Sarah Medland

Secretary, Behavior Genetics Association

Jenae Neiderhiser

Past President, Chair of the BGA Awards Committee

Publisher's Note Springer Nature remains neutral with regard to jurisdictional claims in published maps and institutional affiliations. 